\title{
Editorial
}

\section{A kaleidoscope of selected contributions to hemostasis and thrombosis - an introduction and some editorial remarks}

\author{
Rüdiger E. Scharf ${ }^{1}$ \\ 1 Program in Cellular and Molecular Medicine, Boston Children's \\ Hospital, Harvard Medical School, Boston, MA, USA
}

Hämostaseologie 2020;40:553-556.

COVID-19 has made the year 2020 a tumultuous time and special experience to everyone in- and outside the scientific community worldwide. It can be foreseen that the pandemic will keep us busy and, simultaneously, in a kind of lockdown mode for probably another twelve months.

\section{Persistent challenges}

The unusual association of COVID-19 with severe hemostatic dysregulation and derangements, specifically SARS-CoV-2-induced thromboembolic complications, will remain a challenging task both to clinicians ${ }^{1-7}$ and basic scientists. ${ }^{8,9}$ Importantly, elucidation of disease-related molecular mechanisms and thrombo-inflammatory pathways involved will allow to identify specific targets for therapeutic interventions in order to reduce

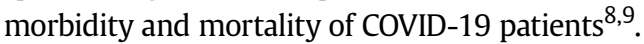

Now, as the year is approaching its end, it appears to be reasonable to share some of the Journal's achievements and highlights during the past 12 months with you. The editorial team of Hämostaseologie - Progress in Haemostasis has tried to do its very best to provide our loyal readers with attractive research articles authored by distinguished scientists in the field. Overall, for the first time in its 40-year history, Hämostaseologie - Progress in Haemostasis is publishing six issues per year, including a supplement of the Hamburg Haemophilia Symposium.

\section{Theme issues in 2020}

We are proud that five of the six editions are true "theme issues" dedicated to hot topics in our field or have been published along with the annual meeting of the Society of Thrombosis and Haemostasis Research (GTH) and the Hamburg Haemophilia Symposium. I appreciate the support of

Address for correspondence Rüdiger E. Scharf, MD, PhD, FAHA, Visiting Professor of Pediatrics, Harvard Medical School, Program in Cellular and Molecular Medicine, Boston Children's Hospital, Karp Family Research Laboratories, 1 Blackfan Circle, RB09211.1, Boston, MA 02115, USA

(e-mail: ruediger.

scharf@childrens.harvard.edu).

many colleagues, specifically the collaboration with Florian Langer and Thomas Renné (issues 1 and 2), Stefano Barco (issue 3), Lorenzo Alberio (issue 4), and Katrin Kurnik and Johannes Oldenburg (supplement) and thank for their timeconsuming task to serve as guest editors. I also wish to acknowledge the flexibility and goodwill of Thieme Publishing Group by supporting our editorial activities and by printing more than 75 scientific articles without page limitations in this year's volume of the Journal.

\section{International awareness and appreciation of the Journal}

Over the past three years, the international awareness of Hämostaseologie - Progress in Haemostasis has been steadily growing. This is reflected by the increasing number of authors from in- and outside of Europe, submitting noninvited reviews, original articles, case reports, commentaries, or letters to the editor.

From January until mid of November 2020, the Editorial Office received more than 95 manuscripts, all of which undergo rigorous review by a section editor and expert referees. The current acceptance rate of manuscripts is $65 \%$ when invited contributions are included but less than $50 \%$ among free submissions. The limited number of the Journal's issues per year does not permit printed publication of submitted free manuscripts close to their acceptance. Therefore, these articles are displayed by "eFirst" mode on the Journal's website and can be referenced by "doi" citation.

\section{Current issue - a kaleidoscope}

The current issue of Hämostaseologie - Progress in Haemostasis provides a perfect example of the Journal's focus and its

(C) 2020 Georg Thieme Verlag KG Rüdigerstraße 14, 70469 Stuttgart, Germany

received

November 16, 2020

accepted

November 17, 2020
DOI https://doi.org/ 10.1055/a-1228-5386. ISSN 0720-9355. 
categories. The articles presented here have in common that they were free submissions that 'survived' the rigorous peer review. Due to realization of all planned theme issues (1 to 4 and the supplement) scheduled in 2020, we decided to compile and print these articles in a separate kaleidoscope-like edition of the Journal.

\section{Guidelines, recommendations, and position papers}

Communication of guidelines, recommendations, and consensus or position papers authored by members of GTH working groups is a key focus of the Journal.

Under the leadership of Katharina Holstein and Christoph Königs, experts from Austria, Germany, and Switzerland of the GTH Standing Committee on Hemophilia Care have developed and approved a practical guidance paper on the use of emicizumab in patients with hemophilia A. ${ }^{10} \mathrm{~A}$ special feature of the Committee's current recommendation is that the major statements are summarized in a table, indicating the degree of consent among the committee members for each statement. The procedure and documentation are appropriate due to the fact that experience with emicizumab is still limited worldwide. A revision of current recommendations may become necessary in the near future.

Christina Hart and prominent members of the GTH Working Group on Women's Health have addressed the task to update recommendations on pharmacological thromboprophylaxis during pregnancy and the puerperium. ${ }^{11}$ Until recently, management strategies for the prevention of venous thromboembolism (VTE) in pregnant and puerperal women were mainly deduced from case-control or observational studies and extrapolated from recommendations for non-pregnant patients. The authors now have compiled evidence from current international studies to establish a rational approach of risk assessment and a more uniform management of pharmacological thromboprophylaxis in pregnant women at risk, thereby focusing on women with hereditary thrombophilia and/or a history of VTE. $^{11}$

\section{Images in thrombosis and hemostasis}

Thromboembolic complications associated with COVID-19 remain a major challenge in the management of affected patients. ${ }^{1-7}$ Currently, the molecular nature of SARS-CoV-2induced thrombo-inflammatory responses is incompletely understood despite many experimental and clinical investigations. $^{8,9}$ In their contribution to the Images in T\&H category, Bingwen Eugene Fan and colleagues from Singapore report on a patient with COVID-9, who, despite adequate anticoagulation, experienced an acute superior mesenteric vein thrombosis in association with acute intestinal obstruction. ${ }^{12}$

\section{Review articles}

Preeclampsia is another clinical condition, in which distinct molecular mechanisms causing endothelial dysfunction and a profound disbalance of hemostatic players remain to be elucidated in detail. In their review, Sarah Kelliher et al. from Dublin discuss recent advances in the pathophysiology of preeclampsia to identify women at risk, prevent thrombotic and/or hemorrhagic complications, and improve the management of patients during pregnancy and the puerperium. ${ }^{13}$ However, the use of antiplatelet and/or anticoagulant drugs in the prevention and treatment of this disorder remains an issue of considerable debate.

Hemophilia care can be a challenging task. This is especially true for patients with severe hemophilia A who develop inhibitor alloantibodies against factor VIII (FVIII), which in turn render subsequent FVIII replacement therapy ineffective. In their contribution, Hans Brackmann and other renowned experts in the field provide a comprehensive review on the management of patients with hemophilia $\mathrm{A}$ and inhibitors, thereby focusing on the use of activated prothrombin complex concentrate. ${ }^{14}$

\section{Original articles}

Hemophilia care is also the topic of two articles submitted by Sylvia von Mackensen et al. In one paper, the investigators have evaluated the impact of two questionnaires, VERITAS-PRO and VERITAS-PRN, to assess adherence of hemophilia patients to treatment and other agreed recommendations (such as diet or life-style changes). Using these American 'adherence tools' both of which are strongly adapted to the US healthcare system, the authors now report that feasibility and application of VERITAS-PRO and VERITAS-PRN are restricted or even unsuitable in the German healthcare system. ${ }^{15}$

In the second paper, the authors report on their "Mobile Hemophilia Outpatient Care" project that has been designed to assess health-related quality of life, treatment satisfaction, and adherence to therapy. ${ }^{16}$ The data of this prospective pilot study document that mobile medical care service can be beneficial to patients with hemophilia, specifically to those with limited access to hemophilia treatment centers.

Inherited disorders of hemostasis, proper identification, and meticulous analysis of their molecular nature are the topic of three original communications presented by investigators from China.

Shaoxi Li et al. describe a novel missense mutation (c.2185G $>A$ ) in exon 6 of the fibrinogen $\alpha$-chain gene ( $F G A$ ), leading to an amino acid exchange in the polypeptide (AoGlu710Lys) and resulting in dysfibrinogenemia. ${ }^{17}$ The fibrinogen variant published here is of particular interest due to its similarity with fibrinogen- 420 , a minor subclass of human fibrinogen (designated " 420 " because of its higher molecular weight compared to fibrinogen-340). ${ }^{18}$ The laboratory phenotype of the A GGlu710Lys fibrinogen variant was characterized by low clotting activity but normal fibrinogen concentration, whereas the clinical phenotype displayed neither bleeding nor thromboembolic events. ${ }^{17}$

In a Letter to the Editor, Siqi Liu et al. report on a Chinese family and demonstrate that a novel missense mutation (c.938T > C) in the SERPINC1 gene resulting in a p.Met281Thr exchange is responsible for a type I antithrombin deficiency. ${ }^{19}$ Structural consequences of the amino acid exchange are also displayed in this short communication. 
Yu Wang et al. studied the molecular basis of factor XII (FXII) deficiency in a Chinese family. ${ }^{20}$ The authors now describe double variants in the $F 12$ gene that are characterized by a heterozygous missense mutation (c.797G $>$ A) leading to p.Cys247Tyr and a deletion mutation (c.809_811delACA) in exon 9 leading to p.252delAsn. It is suggested by the investigators that the two mutations alter the spatial structure of the kringle domain, thereby affecting the protein stability and causing FXII deficiency.

Onco-hemostasis remains a hot topic throughout. Specifically, prevention and treatment of cancer-associated venous thromboembolism (VTE) is in the focus of many clinicians, currently faced with the choice between lowmolecular weight heparin (LMWH) or direct-acting oral anticoagulants (DOAC) for therapeutic management. Which patient-related preferences and features and which physician-related criteria have an impact on the decision making to use either anticoagulant in this setting? In their article, Axel Matzdorf and Florian Langer provide us with preliminary results based on survey data obtained from 115 physicians. ${ }^{21}$ Despite recent recommendations and updated guidelines in favor of DOAC, the debate on which type of anticoagulant should be used in individual patients with cancer-associated VTE will continue.

Patients with non-Hodgkin's lymphoma (NHL) display a high prevalence of antiphospholipid antibodies (APA). The prognostic significance of this association has been discussed controversially. Rimesh Pal et al. from India now report their results of a prospective observational trial demonstrating that APA positivity does not correlate with disease severity, thrombosis risk, clinical outcome, or overall survival in this setting. ${ }^{22}$ These findings are in contrast to a previous report. ${ }^{23}$

Assessment of platelet dysfunction in patients with endstage renal disease and kidney replacement therapy is in the focus of a pilot study by Cenk Gokalp et al. from Turkey. ${ }^{24}$ Using the platelet function analyzer (PFA-100) method, the investigators recorded significantly prolonged closure times in patients undergoing hemodialysis (HD), as compared to patients on peritoneal dialysis (PD). This observation may suggest that PD is a 'gentler' procedure than HD with regard to platelet integrity and viability. However, due to study limitations, these findings need confirmation by a larger number of patients and a longer time of observation.

Drug interactions remain a permanent concern. This is also relevant for the distinct types of DOAC and their different metabolism or elimination. In this context, the analysis by Seyed Hamidreza Mahmoudpour et al. from Mainz is of particular interest, suggesting potential interactions upon combined administration of dabigatran etexilate and interleukin-2, as derived from animal studies in vivo. ${ }^{25}$

\section{Special thanks}

On behalf of the Editorial Board Members I thank the authors for their patience to see their contributions now in print. I also trust that our readers will appreciate this kaleidoscopic issue and honor the authors' efforts to make significant contributions. In particular, I am grateful to the Section Editors and the numerous referees for their valid suggestions and support to improve the authors' work.

At this occasion, I also wish to extend my appreciation and gratitude to Dr. Elinor Switzer and Ms. Susanne Härle for their careful editorial assistance and their perfect trouble shooting whenever required.

As we are terminating this year, we are looking forward to 2021 and the upcoming GTH Congress, an event "simply online ... worth experiencing", as designated by Professor Lorenzo Alberio. ${ }^{26}$ Best wishes to you, our readers - and please stay safe!

\section{References}

1 Bikdeli B, Madhavan MV, Jimenez D, et al. COVID-19 and thrombotic or thromboembolic disease: Implications for prevention, antithrombotic therapy and follow-Up. J Am Coll Cardiol 2020; 75:2950-2973

2 Connors JM, Levy JH. COVID-19 and its implications for thrombosis and anticoagulation. Blood 2020;135:2033-2040

3 Langer F, Kluge S, Klamroth R, Oldenburg J. Coagulopathy in COVID-19 and its implication for safe and efficacious thromboprophylaxis. Hamostaseologie 2020;40:264-269

4 Middeldorp S, Coppens M, van Haaps TF, et al. Incidence of venous thromboembolism in hospitalized patients with COVID-19. J Thromb Haemost 2020;18(08):1995-2002

5 Scharf RE. Productivity of young experts in hemostasis and thrombosis before and during the SARS-CoV-2 pandemic - a special issue. Hamostaseologie 2020;40:255-256

6 Dorgalaleh A. Bleeding and bleeding risk in COVID-19. Semin Thromb Hemost 2020;46:815-818

7 Patell R, Bogue T, Bindal P, et al. Incidence of thrombosis and hemorrhage in hospitalized cancer patients with COVID-19. J Thromb Haemost 2020; Jul 21:10.1111/jth.15018. Doi: 10.1111/ jth.15018

8 Barnes BJ, Adrover JM, Baxter-Stoltzfus A, et al. Targeting potential drivers of COVID-19: Neutrophil extracellular traps. J Exp Med 2020;Jun 1;217(06):e20200652. Doi: 10.1084/jem.20200652

9 Scharf RE, Münzer P, Wagner DD. Basic research in COVID-19: thromboembolism, NETosis, and inflammasome. Dtsch Arztebl Int 2020 (submitted)

10 Holstein K, Albisetti M, Bidlingmaier C, et al. Practical guidance of the GTH haemophilia Board on the use of emicizumab in patients with Haemophilia A. Hamostaseologie 2020;40:561-571

11 Hart C, Bauersachs R, Scholz U, et al. Prevention of venous thromboembolism during pregnancy and the puerperium with a special focus on women with hereditary thrombophilia or prior VTE - position paper of the Working Group in Women's Health of the Society of Thrombosis and Haemostasis Research (GTH). Hamostaseologie 2020;40:572-590

12 Fan BE, Chang CCR, Teo CHYCR, et al. COVID-19 coagulopathy with superior mesenteric vein thrombosis complicated by an ischaemic bowel. Hamostaseologie 2020;40:592-593

13 Kelliher S, Maguire PB, Szklanna PB, et al. Pathophysiology of the venous thromboembolism risk in preeclampsia. Hamostaseologie 2020;40:594-604

14 Brackmann HH, Schramm W, Oldenburg J, et al. Origins, development, current challenges and future directions with activated prothrombin complex concentrate for the treatment of patients with congenital haemophilia with inhibitors. Hamostaseologie 2020;40:606-620

15 von Mackensen S, Douma Y, Halimeh S. Evaluation of the U.S. Adherence Questionnaires VERITAS-PRO and VERITAS-PRN for use in patients with hemophilia in the german healthcare system. Hamostaseologie 2020;40:621-630 
16 von Mackensen S, Schleicher C, Heine S, et al. Health-related quality of life, treatment satisfaction and adherence outcomes of haemophilia patients living in a german rural region. Hamostaseologie 2020;40:631-641

17 Li S, Wang M, Li X, et al. Analysis of an inherited dysfibrinogenemia pedigree associated with a heterozygous mutation in the FGA Gene. Hamostaseologie 2020;40:642-648

18 Mosesson MW, DiOrio JP, Hernandez I, Hainfeld JF, Wall JS, Grieninger $G$. The ultrastructure of fibrinogen- 420 and the fibrin-420 clot. Biophys Chem 2004;112:209-214

19 Liu S, Luo S, Yang L, et al. Phenotypic and genotypic analysis of a hereditary antithrombin deficiency pedigree due to a novel SERPINC1 mutation (p.Met281Thr). Hamostaseologie 2020;40:687-690

20 Wang Y, Zhang H, Liu S, et al. Double heterozygous mutations (Cys247Tyr and 252delAsn) cause factor XII deficiency in a Chinese family. Hamostaseologie 2020;40:650-654

21 Matzdorff A, Langer F. Factors influencing the choice between DOACs and LMWHs: A survey of German physicians on the treatment of cancer-associated venous thromboembolism. Hamostaseologie 2020;40:655-661

22 Pal R, Varma S, Ahluwalia J, et al. Antiphospholipid antibodies are not associated with clinical parameters or prognostic outcomes in patients with non-Hodgkin's lymphoma. Hamostaseologie 2020; 40:662-670

23 Bairey O, Blickstein D, Monselise Y, et al. Antiphospholipid antibodies may be a new prognostic parameter in aggressive nonHodgkin's lymphoma. Eur J Haematol 2006;76:384-391

24 Gokalp C, Karadag FK, Braunisch MC, et al. In vitro closure times (PFA-100) are different between peritoneal dialysis and hemodialysis. Hamostaseologie 2020;40:671-678

25 Mahmoudpour SH, Valerio L, Douxfils J, et al. Potential drug interactions between recombinant interleukin-2 and direct oral anticoagulants: indirect evidence from in vivo animal studies. Hamostaseologie 2020;40:679-686

26 Alberio L. GTH 2021: simply online ... worth experiencing. Hamostaseologie 2020;40:558-559 